\title{
THE ROLE OF THE KIDNEYS IN THE REGULATION OF THE ACID - BASE BALANCE OF THE BLOOD IN PATIENTS WITH CHRONIC OBSTRUCTIVE PULMONARY DISEASE
}

D0I:10.36740/WLek202102121

\author{
Oksana V. Veremiienko, Tatyana S. Ospanova, Zhanna D. Semydotska \\ KHARKIV NATIONAL MEDICAL UNIVERSITY, KHARKIV, UKRAINE
}

\begin{abstract}
The aim: To study the regulation of acid-base balance and blood acid - renal excretory function in patients with COPD.

Materials and methods: We examined 82 people, suggests that even during the most severe stages of COPD. Group 1 included 56 patients with COPD, group C. The average age was $60.54+2.04$ years old, including 24 men and 32 women. The second group included 16 patients with COPD, group B, whose average age was $55.37+3.21$ years old, including 7 men and 9 women. The third group included 10 healthy individuals, with an average age of $34.30+2.21$ years, including 6 men and 4 women. Respiration function was evaluated on the basis of the forced expiratory curve recorded on a Spirolab II MIRS / N computer spirograph. The following indicators were evaluated: forced vital capacity (FVC), forced expiratory volume (FEV1) and FEV1 / FVC ratio.

Results: For all patients with COPD there is a characteristic presence of acidosis ( $\mathrm{pH}$ in patients with COPD group $\mathrm{B}-7,34 \pm 0,01$, in patients with COPD group $C-7,31 \pm 0,07$ ). For patients with COPD group $\mathrm{C}$ there are pronounced respiratory disorders $\left(\mathrm{pCO}_{2}-48,25+1,14 \mathrm{~mm} \mathrm{Hg}, \mathrm{pO}-28.07+1.37 \mathrm{~mm} \mathrm{Hg}\right)$. For patients with COPD group $B$ characteristic metabolic disorders $(\mathrm{BE}--3,71+0,57)$, which increase as the disease progresses. For patients with COPD group C this figure is equal to $7.62+0.49$. Thus, the analysis of indicators indicates the presence for all patients of mixed (respiratory and metabolic) acidosis, which increases as the chronic obstructive pulmonary disease progresses.

Conclusions: There is activation of acid - renal excretory function and the inclusion of renal mechanisms in the regulation of acid-base balance.
\end{abstract}

KEY WORDS: chronic obstructive pulmonary disease, chronic kidney disease, the acid-secreting function of the kidneys, acid based balance

Wiad Lek. 2021;74(2):288-290

\section{INTRODUCTION}

According to statistics, the prevalence of COPD among adults is about $4-6 \%$ [1]. If COPD ranked 6th among the causes of death in 1990, then next year they are projected to occupy the 3 rd place. In the age group over 45 , COPD is now ranked 4 th among the causes of death. Within 3 years after hospitalization of patients with COPD for exacerbations, the overall mortality rate is $49 \%$. In this regard, timely diagnosis and effective treatment of COPD has become an increasingly urgent problem in modern pulmonology [2,3]. Chronic obstructive pulmonary disease (COPD) and chronic kidney disease (CKD) affect a large number of patients. The World Health Organization estimates COPD to become the 3rd leading cause of mortality worldwide in 2030 [1]. CKD, defined by abnormalities of kidney structure or function for more than 3 months [2], affected $14.8 \%$ of the U.S. adult general population in 2011-2014 [3]. Cigarette smoking and increasing age are risk factors for the development of both COPD and CKD [4-6], with systemic inflammation as an extrapulmonary manifestation of COPD potentially increasing the risk of comorbid CKD [7]. This combination of COPD and CKD is independently associated with a higher prevalence of other comorbidities (especially cardiovascular) and increased mortality $[8,9]$.
Cardiovascular dysfunction is a well-known predictor of a limited functional capacity and health status [10]. Whether CKD and kidney function have a role for functional limitations independent of established cardiovascular disease is currently unknown.

\section{THE AIM}

To study the regulation of the acid-base balance of the blood and the acid-secreting functions of the kidneys in patients with COPD group B and C.

\section{MATERIALS AND METHODS}

In the Pulmonology Department of Kharkiv Regional Hospital, we examined 82 people, which are divided into 3 groups. Group 1 included 56 patients with COPD, group C. The average age was $60.54+2.04$ years old, including 24 men and 32 women. The second group included 16 patients with COPD, group B, whose average age was $55.37+3.21$ years old, including 7 men and 9 women. The third group included 10 healthy individuals, with an average age of $34.30+2.21$ years, including 6 men and 4 women.

Respiration function was evaluated on the basis of the forced expiratory curve recorded on a Spirolab II MIR S / N 
Table I. Clinical characteristics of patients.

\begin{tabular}{ccc}
\hline Diagnosis / indicators & COPD gr. B & COPD gr. C \\
\hline Dyspnea & $100,00 \pm 0,28$ & $100,00 \pm 3,01$ \\
\hline Cough & $100,0010,28$ & $100,00+3,01$ \\
\hline With sputum & $54,5+15,02$ & $50,00 \pm 15,07$ \\
\hline Fever & $18,2 \pm 13,64$ & 0 \\
\hline Asthma attack & $87,5 \pm 11,69$ & $100,00 \pm 3,01$ \\
\hline Dry rails & $100,00+0,28$ & $100,00 \pm 3,01$ \\
\hline Bandbox sound due to percussion of the lung & $62,5+17,11$ & $54,50 \pm 5,01$ \\
\hline $\begin{array}{c}\text { X ray of respiratory organs: deformation a pulmonary drawing, } \\
\text { increasing of transparency of lungs }\end{array}$ & $50,00 \pm 17,67$ & $36,40 \pm 4,50$
\end{tabular}

Table II. Indicators of respiratory function in patients with COPD.

\begin{tabular}{cccc}
\hline Diagnosis / indicators & Control group & COPD gr. B & COPD gr. C \\
\hline & $\mathrm{n}=10$ & $\mathrm{n}=16$ & $\mathrm{n}=56$ \\
\hline $\mathrm{FVC}(\%)$ & $94,0013,30$ & $80,2314,05^{*}$ & $57,53+2,42^{* *}$ \\
\hline $\mathrm{FEV}_{1}(\%)$ & $102,2014,50$ & $74,1515,14^{*}$ & $44,42+3,24^{* *}$ \\
\hline $\mathrm{FEV}_{1} / \mathrm{VC}(\%)$ & $105,0010,06$ & $73,32+5,67^{*}$ & $69,4713,39^{* *}$ \\
\hline
\end{tabular}

* $-p<0.05$ compared with the control group

$* *-p<0,05$ when comparing the indicators with the control group and COPD

computer spirograph. The following indicators were evaluated: forced vital capacity (FVC), forced expiratory volume $\left(\mathrm{FEV}_{1}\right)$ and $\mathrm{FEV}_{1} / \mathrm{FVC}$ ratio.

The following indicators of gas and acid-general composition of venous blood were studied using Bayer 348 gas analyzer: $\mathrm{pH}$, partial pressure of carbon dioxide $\left(\mathrm{pCO}_{2}\right)$ and oxygen $\left(\mathrm{p}_{2}\right)$, plasma bicarbonate $\left(\mathrm{HCO}_{3}\right)$, deficiency or excess of buffer bases (BE).

The acid-secreting function of the kidneys was investigated by measuring the excretion of titratable acids (E t.a.), the excretion of ammonium $\left(\mathrm{E}_{\mathrm{MH}}\right)$ and the determination of excretion of hydrogen ions $(\mathrm{E} n+)$.

\section{RESULTS AND DISCUSSION}

As can be seen from table 1, all patients with COPD had shortness of breathing and cough. Half of the patients had cough accompanied by sputum. An increase in body temperature was observed in $18.20 \%$ of patients with COPD, group B. In the group of patients with COPD, group C body temperature was within normal range. In $100 \%$ of patients with COPD, group C, and in $87.5 \%$ of patients with COPD, group B asthma attacks were noted.

In $62.5 \%$ of patients with COPD, group B and in $54.5 \%$ of patients with COPD, group $\mathrm{C}$ in the percussion of the lungs a bandbox sound was noted. During auscultation of the lungs, the presence of rigid breathing and crackling wheezing was noted in all examined patients, both with COPD, group B and C. Due to $\mathrm{X}$ - ray examination, deformation of the pulmonary pattern were noted in $75.00 \%$ of patients with COPD, group B and $81.80 \%$ in patients with COPD, group C. Increased lung transparency was observed in $50.00 \%$ of COPD, group $\mathrm{B}$ and $36.40 \%$ of COPD, group C in accordance.
The results of the study of the function of external respiration are presented in table 2 . As can be seen from table 2, for patients with COPD, group B compared to the control group, there is a marked decrease in forced lung capacity (FVC), forced expiratory volume $\left(\mathrm{FEV}_{1}\right)$, and $\mathrm{FEV}_{1} / \mathrm{VC}$.

In the group of patients with COPD group $\mathrm{C}$ recorded $44.42+3.24 \%$. Thus, function indicators further reduce these indicators. Thus, FVC external respiration in all patients indicate a significant reduction to $57.53+2.42 \%$, $\mathrm{FEV}_{1}$ ventilatory disorders, which often leads to an increase in the disproportionate ratio of ventilation / overload and gas exchange disorders.

Indicators of acid-base status of blood in these patients are presented in table 3 . For all patients with COPD there is a characteristic presence of acidosis $(\mathrm{pH}$ in patients with COPD group $B-7,34 \pm 0,01$, in patients with COPD group $\mathrm{C}-7,31 \pm 0,07)$. For patients with COPD group $\mathrm{C}$ there are pronounced respiratory disorders ( $\mathrm{pCO} 2-48,25+$ $1,14 \mathrm{~mm} \mathrm{Hg}, \mathrm{p} 02-28.07+1.37 \mathrm{~mm} \mathrm{Hg}$ ). For patients with COPD group B characteristic metabolic disorders (BE-$3,71+0,57)$, which increase as the disease progresses. For patients with COPD group C this figure is equal to $7.62+$ 0.49 . Thus, the analysis of indicators indicates the presence for all patients of mixed (respiratory and metabolic) acidosis, which increases as the chronic obstructive pulmonary disease progresses.

At these stages, COPD shows active involvement of the kidneys in the compensatory processes, as evidenced by the indicators in Table. 3. Participation of kidneys in compensation of acidosis in patients with COPD is carried out at the expense of statistically significant increase in excretion of hydrogen ions (in patients with COPD group B $-109.95+10.12 \mathrm{mmol} / \mathrm{dl}$ ). The increase in the excretion 
Table III. Acid-alkaline state of blood and acid-secreting functions of kidneys in patients with COPD

\begin{tabular}{|c|c|c|c|}
\hline Diagnosis / indicators & $\begin{array}{l}\text { Control group } \\
\qquad n=10\end{array}$ & $\begin{array}{c}\text { COPD gr. B } \\
n=16\end{array}$ & $\begin{array}{c}\text { COPD gr. C } \\
n=56\end{array}$ \\
\hline & $7,40 \pm 0,01$ & $7,34+0,01^{*}$ & $7,31+0,07$ \\
\hline $\mathrm{BE} \mathrm{mk} / \mathrm{l}$ & $0,36+0,01$ & $-3,71+0,57^{*}$ & $-7,62+0,49^{* *}$ \\
\hline $\mathrm{pO}_{2^{\prime}} \mathrm{mm} \mathrm{Hg}$ & $39,30+4,30$ & $41,11+4,37$ * & $28,07+1,37^{* *}$ \\
\hline $\mathrm{pCO}_{2^{\prime}} \mathrm{mm} \mathrm{Hg}$ & $39,20 \pm 0,15$ & $4.1,70+2,72 *$ & $48,25+1,14^{* *}$ \\
\hline Et.a. $\mathrm{mmol} / \mathrm{dl}$ & $27,52 \pm 0,33$ & $33,62+2,62$ & $36,15+2,60 * *$ \\
\hline $\mathrm{E}_{\mathrm{NH}^{\prime}} \mathrm{mmol} / \mathrm{dl}$ & $47,33+0,057$ & $61,23+3,97^{*}$ & $73,81+7,52$ \\
\hline $\mathrm{E} \mathrm{H+}, \mathrm{mmol} / \mathrm{dl}$ & $74,85+6,59$ & $94,85+0,42^{*}$ & $109,95+10,12^{*}$ \\
\hline
\end{tabular}

$*$ - $p<0.05$ compared with the control group

$*^{* *}-p<0,05$ when comparing the indicators with the control group and COPD

of hydrogen ions in both groups of patients is due to the increased excretion of titratable acids and ammonium. It should be noted that the highest excretion of titratable acids $(36,15+02,60 \mathrm{mmol} / \mathrm{d})$ and ammonium $(73,81+7,52$ $\mathrm{mmol} / \mathrm{dl}$ ) takes place in the COPD group C. The analysis of these indicators shows that even at the most difficult stages of COPD, there is an activation of the acid-secreting function of the kidneys and the involvement of the renal mechanisms in the regulation of acid balance.

\section{CONCLUSIONS}

1. For patients with COPD characterized by severe ventilatory disorders, which are a decrease in the rate of forced lung capacity, forced expiratory volume and FEV,/VC.

2. Indicators of acid-base balance reflect the degree of progression of COPD and are characterized by signs of respiratory, metabolic and mixed acidosis.

3. The kidneys are actively involved in the regulation of CLS in patients with COPD group B and COPD group $\mathrm{C}$ by increasing the excretion of titratable acids and ammoniogenesis.

\section{REFERENCES}

1. Chronic respiratory diseases. 2019. http://www.who.int/respiratory/ copd/burden/en/.

2. Inker L.A., Astor B.C., Fox C.H. et al. KDOQI US commentary on the 2012 KDIGO clinical practice guideline for the evaluation and management of CKD. Am J Kidney Dis. 2014;63(5):713-35.

3. Saran R., Robinson B., Abbott K.C. et al. US renal data system 2016 annual data report: epidemiology of kidney disease in the United States. Am J Kidney Dis. 2017;69(3):A7-8.

4. Vogelmeier C.F., Criner G.J., Martinez F.J. et al. Global strategy for the diagnosis, management, and prevention of chronic obstructive lung disease 2017 report: GOLD executive summary. Eur Respir J. 2017;49(3):1-32.

5. Haroun M.K., Jaar B.G., Hoffman S.C. et al. Risk factors for chronic kidney disease: a prospective study of 23,534 men and women in Washington County. Maryland J Am Soc Nephrol. 2003;14(11):2934-41.

6. Fox C.S., Larson M.G., Leip E.P. et al. Predictors of new- onset kidney disease in a community-based population. J Am Med Assoc. 2004;291(7):844-50.
7. Miyamoto T., Carrero J.J., Stenvinkel P. Inflammation as a risk factor and target for therapy in chronic kidney disease. Curr Opin Nephrol Hypertens. 2011;20(6):662-8.

8. Navaneethan S.D., Schold J.D., Huang H. et al. Mortality outcomes of patients with chronic kidney disease and chronic obstructive pulmonary disease. Am J Nephrol. 2016;43(1):39-46.

9. van Gestel Y.R., Chonchol M., Hoeks S.E. et al. Association between chronic obstructive pulmonary disease and chronic kidney disease in vascular surgery patients. Nephrol Dial Transplant. 2009; 24(9):2763-7.

10. Houben-Wilke S., Jorres R.A., Bals R. et al. Peripheral artery disease and its clinical relevance in patients with chronic obstructive pulmonary disease in the COPD and systemic consequences- comorbidities network study. Am J Respir Crit Care Med. 2017;195(2):189-97.

\section{ORCID and contributionship:}

Oksana V. Veremiienko: 0000-0002-8778-6805 B,C,D

Tatyana S. Ospanova: 0000-0002-5036-6639 ${ }^{E, F}$

Zhanna D. Semydotska: 0000-0002-0402-9463 ${ }^{A}$

\section{Conflict of interest:}

The Authors declare no conflict of interest.

\section{CORRESPONDING AUTHOR}

Oksana V. Veremiienko

Kharkiv national medical university

4 Nauki str., 61000 Kharkiv, Ukraine

tel: +380999188430

e-mail: oksveremeenko@gmail.com

Received: 07.04 .2020

Accepted: 19.11 .2020
A - Work concept and design, B - Data collection and analysis, C - Responsibility for statistical analysis,

D-Writing the article, $\mathbf{E}-$ Critical review, $\mathbf{F}$ - Final approval of the article 